\section{COMPUTER-AIDED DESIGN OF TECHNOLOGY FOR PRODUCING SOLID LUBRICATING COATING ON TOOL STEEL}

\section{ALEXANDER SHMATOV ${ }^{1}$, LUBOMIR SOOS ${ }^{2}$, ZDENKO KRAJNY²}

\author{
${ }^{1}$ Belarusian National Technical University, Faculty of \\ Mechanical Engineering, Minsk, Belarus \\ ${ }^{2}$ Slovak Technical University, Faculty of Mechanical \\ Engineering, Bratislava, Slovakia \\ DOI : 10.17973/MMSJ.2019_12_2019041 \\ e-mail: shmatovalexander@gmail.com
}

This article deals with the new method for producing solid lubricating coatings on steel tools by thermo-hydrochemical treatment (THCT). The results of investigation of tribological properties of the coatings fabricated on high carbon steel of $\mathrm{y} 8$ grade $(0,8 \mathrm{wt} . \% \mathrm{C})$ using THCT method are presented. The composition of the medium and the temperature and the time parameters of THCT process were optimized by the friction coefficient of solid lubricating coatings. The diagrams of "parameters of process-property" were constructed using mathematical models. Processing by optimal THCT regime of y8 steel in hydrosol medium based on $\mathrm{TiO}_{2}-\mathrm{MoO}_{3}$ makes it possible under the condition of lubrication absence to decrease the friction coefficient of steel surface by 8.3 times as compared with untreated.

KEYWORDS:

Thermo-hydrochemical treatment, solid lubricating coating, tool steel

\section{INTRODUCTION}

The problem of increasing the service life of steel tools, machining accessories, and machine parts remains relevant as before. There are various hardening methods of solving it. A lot of scientific researches are carried out on the development of wear-resistant ceramic coatings obtained by PVD (physical vapor deposition) methods, CVD (chemical vapor and gas deposition), spraying, and TCHT (thermochemical heat treatment) in vacuum, which are activated by nonconventional sources of heating (plasma, laser, electron beam, etc.). However, these hardening methods have a number of disadvantages, the main ones of which are (1) high temperatures of processes, which lead to deformation of products and weakening of the initial matrix; (2) low productivity and complexity of processes; (3) large labor intensiveness and energy capacity of processes; (4) environmental degradation and harmful energy effect on human health; (5) high cost of equipment and components to be applied; etc. [Hocking 1989], [Cavaleiro 2006], [Shmatov 2018]. So the process of thermo-hydrochemical treatment
(THCT) is of the greatest scientific and practical interest, because it is distinguished by efficiency and high productivity, it makes it possible to fabricate coatings based on any ceramic materials, it is applicable to operation-ready products of various steels and alloys, and it slightly changes their initial sizes, shape, and structure [Shmatov 1998], [Shmatov 2014], [Shmatov 2016].

THCT is intended to chemically deposit on the surfaces of various materials antifriction solid lubricating coatings, which possess spare capacities in rugged and catastrophic operating conditions of tools and machinery [Shmatov 2014]. The coatings acquire solid lubricating properties in the following cases: (a) when they are fabricated of materials with layered polycrystalline structure (graphite, sulfides, etc.); (b) when they are formed on the basis of nanostructured refractory and ultrahard materials; (c) the Bernal theory is implemented, according to which any solid body acquires the properties of fluid if the crystal lattice contains more than $10 \%$ of vacancies; (d) the Rebinder effect is implemented, which leads to the plasticization of surface layer and creation of a positive gradient of mechanical properties in the friction zone; (e) the Kirkendall effect is implemented, which leads to selective dissolution of alloying elements from alloy owing to the differences in their electrochemical potentials, resulting in a quasi-liquid film being formed, which reduces friction coefficient and frictional heating [Polzer 1983].

THCT is the easiest and most universal method of fabricating solid lubricating coatings. Using the method, one can fabricate nanostructured coatings based on oxides, sulfides, carbides, diamond, carbon, and other antifriction materials [Shmatov 2014]. When fabricating such coatings, the Rebinder effect is implemented owing to introduction into an aqueousdispersion medium of surface-active materials (SAM). The fabricated nanostructured coatings have superplasticity, and they facilitate the gap of adhesive joints in the friction zone; at the same time, the hardness of nanomaterials of metals and refractory compounds increases by 2-3 times [Cavaleiro 2006]. According to vacancy-diffusion and adhesion-deformation mechanisms of friction, increasing the wear resistance of solids is achieved by a combination of the above-mentioned effects: high hardness of its surface and low strength of adhesive bond [Polzer 1983].

Since in most cases as a result of THCT, the initial structure is preserved (is not weakened), and final dimensions and shape of products hardly change, these coatings can be deposited to ready-to-use tools and machine components. On the other hand, under the conditions of intense operation of products when there is no lubricant in the friction zone or its supply is limited, the best way to reduce the friction of working parts of products is depositing solid lubricating coatings on them [Vityaz' 2007], [Shmatov 2016].

From the above presented analysis, it follows that the THCT process has great prospects for its development, especially for tools with a small operating life. In this regard, special attention should be paid to unalloyed tool steels (of $\mathrm{y} 8, \mathrm{y} 10$, y12, etc., grades), which owing to their low cost are widely used to fabricate various types of stamps.

The mathematical methods of planning experiments can render great assistance to the researcher when there is a 
labor-intensive choice of optimal variant of THCT process of steels and alloys. These methods make it possible to obtain a maximum of information with minimum costs. In materials science, traditionally direct problems are solved when, on the basis of the minimum number of experiments conducted under the preset temperature and time conditions (according to the plan of experiments), the properties of the material are defined; then the mathematical models describing the influence of factors are constructed and using graphical interpretation the optimal parameters of the process are chosen [Novik 1971]. However, such an approach can not solve the whole set of problems arising when designing technology, as the operation of any technological system (in this case, it is the technology of THCT of y8 steel in hydrosol medium based on $\mathrm{TiO}_{2}-\mathrm{MoO}_{3}$ ) occurs under the conditions of constant random change of values of the system parameters under the influence of various external and internal destabilizing factors. Technological systems themselves as the design objects have a number of specific properties: multicriteriality, multiparametricity, stochasticity (spread of parameters), presence of nonlinear intrasystem bonds, etc. When studying, designing, and developing such objects, it is necessary to solve not only direct problems and inverse ones, where the researcher specifies a sets of necessary properties of the material in advance and using a computer simulation finds optimal time-temperature parameters of the process. This methodological approach, which is called the multidimensional designed synthesis of technological system, is successfully applied when developing new technologies and materials [Vityaz' 1971], [Shmatov 2014], [Shmatov 2016].

In connection with the aforementioned, the objective of this work was optimization and computer-aided design of THCT technology for fabricating on $\mathrm{y} 8$ steel a solid lubricating coating based on $\mathrm{TiO}_{2}-\mathrm{MoO}_{3}$ owing to application of the method of multidimensional design synthesis of technical objects, materials, and technologies.

\section{METHODS}

y8 steel, which is widely used in practice, has been subjected to thermo-hydrochemical treatment. The THCT process itself was carried out by conducting two of operations: (a) hydrochemical treatment (HCT) of steel surface at the temperature of $96-100^{\circ} \mathrm{C}$ for $10-420 \mathrm{~min}$ in a specially prepared aqueous suspension based on dispersed oxides $\mathrm{TiO}_{2}$ and $\mathrm{MoO}_{3}$; (b) subsequent thermal treatment (TT) under heating in an oxidative medium to the temperature of 130 $1050^{\circ} \mathrm{C}$, holding for $20-30 \mathrm{~min}$, and cooling in air. The aqueous suspension was previously prepared by special technology upon mixing nano- and ultradimensional $(0.1-1 \mu \mathrm{m})$ grains of oxides with $4-8 \%$ of sulfanol (which was used as surface-active material - SAM). The working composition with acidity $\mathrm{pH} 6-$ 8 was considered ready. The desired acidity was set and maintained by dosed introduction of $\mathrm{NH}_{4} \mathrm{OH}$. When conducting $\mathrm{HCT}$, the specimens were placed and stored in a bath with the ready work composition, heated to the temperature of the process. The surface of specimens was previously degreased in white spirit and pickled in a 5-10\% sulfuric acid solution for 12 min. After each HCT operation, the specimens were washed in water. Isothermal storage of steel at temperatures up to $200^{\circ} \mathrm{C}$ was carried out in air, and at temperatures higher than $200^{\circ} \mathrm{C}$, the storage was carried out in a protective medium.

To determining the tribotechnical characteristics of solid lubricating thermo-hydrochemical coatings with a microtribometer (Fig. 1), specimens with size of $10 \times 10 \mathrm{~mm}$ were used.

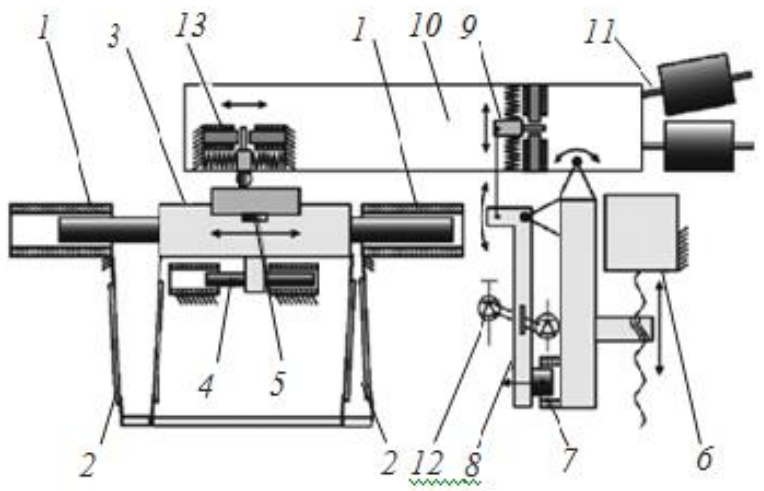

Figure 1. Reciprocating microtribometer with maximum applied load of $1 \mathrm{~N}$ (manufactured by MPRI, Gomel, Belarus):

(1) electromagnets of drive; (2) guides of bend; (3) table holder of specimen; (4) position sensor; (5) triboacoustical emission sensor; (6) incremental drive; (7) electromagnet of loading system; (8) lever; (9) load sensor; (10) head; (11) balance weights; (12) optical coupler; (13) friction force sensor.

When designing the technological process of THCT of $\mathrm{y}_{8}$ tool steel, we applied the synthesis technologies of the method of multidimensional design synthesis of technological objects, materials, and technologies in the form of basic computer software-SINTEZ MK software [Vityaz' 1971]. The proposed method makes it possible to operate not only with the mathematical criteria but also with the technical criteria of optimality. To implement the procedures of multidimensional design synthesis of the technological system when carrying out the THCT of $\mathrm{y} 8$ steel, a set of new methods was used, the most significant of which are the following: the method of solving the inverse multicriterial problem; the method of computer selection of the technically optimal variant; the method of allocation of stability domains of the studied technological system in the multidimensional space of technological parameters; and the method of constructing a graphical representation of states of the technological system.

The method of multidimensional design synthesis of the technological system, unlike the traditional optimization method [Novik 1971], makes it possible to do the following:

(1) to select the technically optimal variant which possesses the greatest resistance to the impact of destabilizing factors of manufacture;

(2) simultaneously to solve the inverse multicriterial problems: to allocate in a space of the system the stable domains and select the technically optimal variant of the technological system in one of the stable domains when ensuring the desired level of the reproducibility of material properties;

(3) to select in the space of technological parameters the domain of a steady state of the system in which the specified properties of the materials are achieved and stably reproduced simultaneously. 


\section{RESEARCH RESULTS}

To design a new THCT process, y8 steel was subjected to hydrochemical treatment in hydrosol containing $\mathrm{TiO}_{2}-\mathrm{MoO}_{3}$ when heating to a temperature close to the boiling point for 50-70 min, and tempering was carried out at a temperature of $160-200^{\circ} \mathrm{C}$. Under such conditions at THCT of y8 steel, solid lubricating coatings based on $\mathrm{TiO}_{2}-\mathrm{MoO}_{3}$ with the best antifriction properties are formed (Fig. 2).

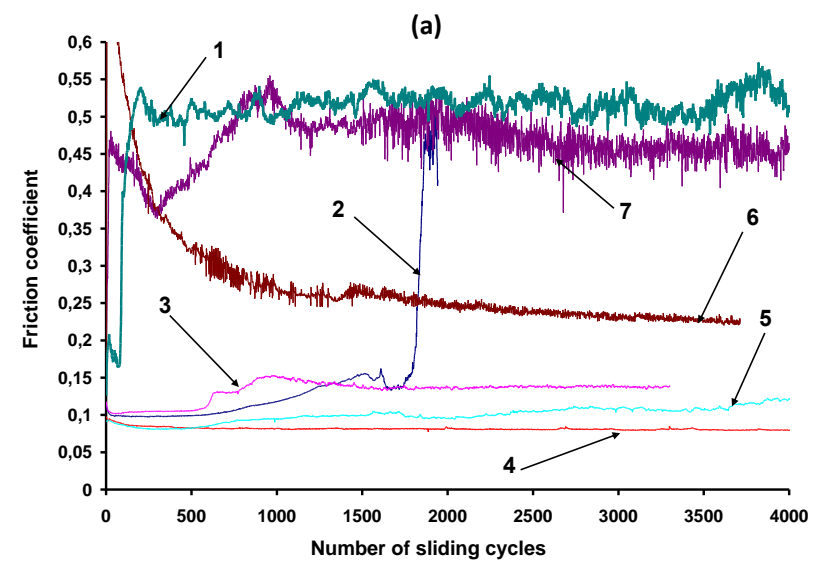

(b)

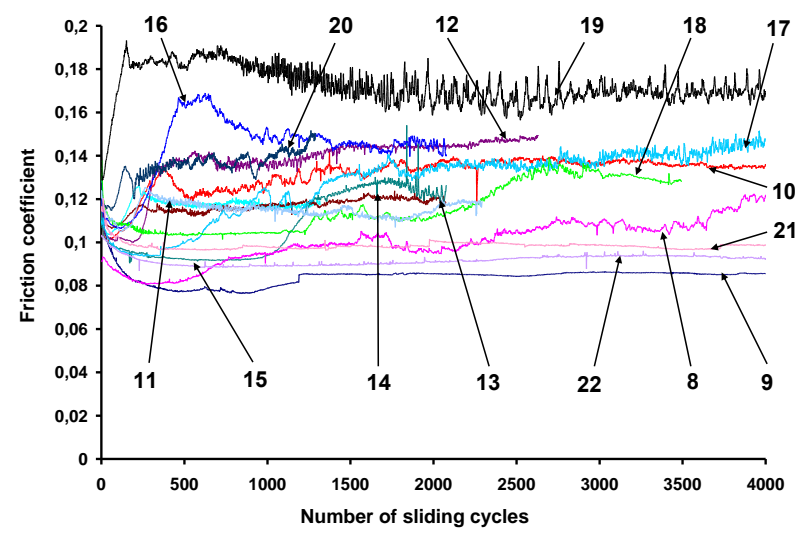

Figure 2. Influence of parameters of THCT process on the friction coefficient of $\mathrm{Y} 8$ steel. THCT conditions are hydrosol for HCT based on $\mathrm{TiO}_{2}-\mathrm{MoO}_{3}$ : (a) $\mathrm{HCT}$ at $T=100{ }^{\circ} \mathrm{C}$ without tempering; (b) tempering at TT $\tau=0.5 \mathrm{~h}$ after $\mathrm{HCT}$ at $T=100{ }^{\circ} \mathrm{C}, \tau=2 \mathrm{~h}$.

Test conditions are dry sliding friction (without lubrication); friction pair is hardened Y8 steel (plane) - ШX15 steel (sphere $4 \mathrm{~mm}$ in diameter); load is $1 \mathrm{~N}$; stroke length (track) is $3 \mathrm{~mm}$, speed is $4 \mathrm{~mm} / \mathrm{s}$. $1-\mathrm{y} 8$ steel (before treatment); HCT conditions: $2-10 \mathrm{~min} ; 3-30$ $\min ; 4-60 \mathrm{~min}$; $5-120 \mathrm{~min} ; 6-240 \mathrm{~min}$; $7-420 \mathrm{~min}$;

TT conditions: $8-100{ }^{\circ} \mathrm{C} ; 9-200{ }^{\circ} \mathrm{C} ; 10-250{ }^{\circ} \mathrm{C} ; 11-300{ }^{\circ} \mathrm{C} ; 12-$ $350{ }^{\circ} \mathrm{C} ; 13-400{ }^{\circ} \mathrm{C} ; 14-450{ }^{\circ} \mathrm{C} ; 15-500{ }^{\circ} \mathrm{C} ; 16-550{ }^{\circ} \mathrm{C} ; 17-600$ ${ }^{\circ} \mathrm{C} ; 18-650{ }^{\circ} \mathrm{C} ; 19-700{ }^{\circ} \mathrm{C} ; 20-870{ }^{\circ} \mathrm{C} ; 21-1000{ }^{\circ} \mathrm{C} ; 22-1050{ }^{\circ} \mathrm{C}$.

In optimization of the process, only the temperature and time of hydrochemical treatment, the fractional content of the basic component of the chemically active medium, and the tempering temperature were varied. In the present work, the volume fraction and the morphology of initial particles of $\mathrm{TiO}_{2}$ and $\mathrm{MoO}_{3}$ were not taken into account since they affect the tribological properties of fabricated coatings very little, which is related to modification of all structural parameters of particles during hydrochemical nanodispersion up to hydrosol formation. The results of tribotechnical tests of the thermohydrochemical hardened y8 steel obtained upon implementation of 8 experiments of the test plan [Novik 1971] are presented in Tab. 1.

\begin{tabular}{|c|c|c|c|c|c|}
\hline \multirow{3}{*}{$\begin{array}{c}\text { Experiment } \\
\text { number }\end{array}$} & \multicolumn{4}{|c|}{ Factors } & \multirow{3}{*}{\begin{tabular}{|c} 
Parameter \\
of \\
optimization
\end{tabular}} \\
\hline & \multicolumn{3}{|c|}{ Hydrochemical treatment } & \multirow{2}{*}{\begin{tabular}{|c|}
$\begin{array}{c}\text { Thermal } \\
\text { treatment }\end{array}$ \\
$\begin{array}{c}\text { Tempe- } \\
\text { rature } \\
T,{ }^{\circ} \mathrm{C}\end{array}$ \\
\end{tabular}} & \\
\hline & $\begin{array}{c}\text { Tempe- } \\
\text { rature } \\
T,{ }^{\circ} \mathrm{C}\end{array}$ & $\begin{array}{c}\text { Time, } \\
\tau, \\
\min \end{array}$ & \begin{tabular}{|c|}
$\mathrm{MoO}_{3}$ in \\
oxides \\
mixture, \%
\end{tabular} & & \\
\hline Designation & $X_{1}$ & $X_{2}$ & \begin{tabular}{l|}
$X_{3}$ \\
\end{tabular} & $X_{4}$ & $Y_{1}$ \\
\hline Basic level $(0)$ & 98 & 60 & 50 & 180 & \\
\hline Variation interval & 2 & 10 & 10 & 20 & \\
\hline Upper level (+1) & 100 & 70 & 60 & 200 & \\
\hline Lower level $(-1)$ & 96 & 50 & 40 & 160 & \\
\hline 1 & + & + & + & + & 0,068 \\
\hline 2 & - & + & + & - & 0,072 \\
\hline 3 & + & - & + & - & 0,076 \\
\hline 4 & - & - & + & + & 0,070 \\
\hline 5 & + & + & - & + & 0,069 \\
\hline 6 & - & + & - & - & 0,075 \\
\hline 7 & + & - & - & - & 0,082 \\
\hline 8 & - & - & - & + & 0,073 \\
\hline
\end{tabular}

Table 1. The results of investigation of the friction coefficient of coatings on $\mathrm{y} 8$ steel fabricated with THCT in hydrosol based on $\mathrm{TiO}_{2}-$ $\mathrm{MoO}_{3}$

On the basis of these data, the linear and nonlinear mathematical models describing the influence of temperature and time parameters and composition of active mixtures on the friction coefficient of THC of solid lubricating coatings based on $\mathrm{TiO}_{2}-\mathrm{MoO}_{3}$ were calculated. However only the nonlinear multicriterial mathematical models of following form were recognized as adequate:

$$
\begin{aligned}
& Y_{1}=73,13 \cdot 10^{-3}-0,75 \cdot 10^{-3} X_{1}-1,75 \cdot 10^{-3} X_{2}-3,0 \cdot 10^{-3} X_{3}- \\
& 4,5 \cdot 10^{-3} X_{4}+7,5 \cdot 10^{-4} X_{1} X_{3}-7,5 \cdot 10^{-4} X_{2} X_{3}+6,25 \cdot 10^{-3} X_{1} X_{3}
\end{aligned}
$$

where $Y_{1}$ is the friction coefficient, $X_{1}$ is the temperature of hydrochemical treatment, $X_{2}$ is the time of hydrochemical treatment, $\mathrm{X}_{3}$ is the $\mathrm{MoO}_{3}$ percentage in oxides $\mathrm{TiO}_{2}-\mathrm{MoO}_{3}$ mixture of hydrosol, and $X_{4}$ is the tempering temperature.

Owing to multicriteriality, stochasticity, and nonlinearity of "the THCT process of y8 steel" technological system, the prediction of its behavior is complicated. The values of parameters of each actual object differ from the designed ones and are randomly distributed in a scatter band. As a consequence, there is no guarantee that all points of optimization of the actual system will be placed in the stable domain, i.e., it is not always possible to improve the material properties up to the desired its level. So that this does not happen, when designing the technological process, a certain system stability margin is provided, which makes it possible to avoid a degradation of the quality of system functioning by the criterion of reproducibility of material properties.

Under the traditional methodology of optimization of system parameters, the solutions of the problems of technological designing of the system are not entirely correct, as the processes are considered as deterministic ones, i.e., passing under adherence of precise values of technological system 
parameters. In fact, deterministic systems do not exist, as the values of parameters of actual technology systems always are random and the systems themselves are stochastic. The selection of a technically optimal variant of THCT of y8 steel in hydrosol of $\mathrm{TiO}_{2}-\mathrm{MoO}_{3}$ was carried out with the method of computer-aided design of technology systems with the help of the specially developed SINTEZ MK software program, which is intended to solving nonlinear and stochastic tasks for providing for whole working capacity of technological systems.

The computer-aided design of THCT technology of y8 steel using SINTEZ MK software was carried out in several stages. The results of the selection of the optimum variant of the studied technological systems are summarized in Tab. 2 and 3. While solving the inverse multicriterial problem, the desired limit values of properties of solid lubricating coatings fabricated with THCT of y8 steel were set (Tab. 4). The manufacturing tolerance margins of technological system by input parameters are presented in Tab. 5. For graphical interpretation of the results obtained when solving the tasks of the research and design of THCT technology of the y8 steel in hydrosol based on $\mathrm{TiO}_{2}-\mathrm{MoO}_{3}$, discrete portraits were constructed (Fig. 3).

\begin{tabular}{|l|c|c|}
\hline \multicolumn{1}{|c|}{ Name of process parameter } & $\begin{array}{c}\text { Rated } \\
\text { value }\end{array}$ & $\begin{array}{c}\text { Permissible } \\
\text { scatter bands }\end{array}$ \\
\hline Temperature of hydrochemical treatment, ${ }^{\circ} \mathrm{C}$ & 100 & 4 \\
\hline Time of hydrochemical treatment, min & 67 & 9 \\
\hline $\mathrm{MoO}_{3}$ percentage in oxides mixture $\%$ & 57 & 8 \\
\hline Tempering temperature, ${ }^{\circ} \mathrm{C}$ & 189 & 22 \\
\hline
\end{tabular}

Table 2. Optimal parameters of the THCT process of $y 8$ steel in hydrosol based $\mathrm{TiO}_{2}-\mathrm{MoO}_{3}$ and their scatter bands

\begin{tabular}{|c|c|c|}
\hline $\begin{array}{c}\text { Name of optimal index of } \\
\text { properties }\end{array}$ & Rated value & Scatter band \\
\hline Friction coefficient, $f$ & 0,067 & 0,013 \\
\hline
\end{tabular}

Table 3. Optimal indices of properties of solid lubricating coatings fabricated with THCT of $\mathrm{Y} 8$ steel in hydrosol based on $\mathrm{TiO}_{2}-\mathrm{MoO}_{3}$ and their scatter bands

\begin{tabular}{|c|c|c|}
\hline $\begin{array}{c}\text { Name of desired index of } \\
\text { properties }\end{array}$ & Minimum value & Maximum value \\
\hline Friction coefficient, $f$ & 0,060 & 0,075 \\
\hline
\end{tabular}

Table 4. Set limits of properties of solid lubricating coatings fabricated with THCT of $\mathrm{Y} 8$ steel in hydrosol based on $\mathrm{TiO}_{2}-\mathrm{MoO}_{3}$
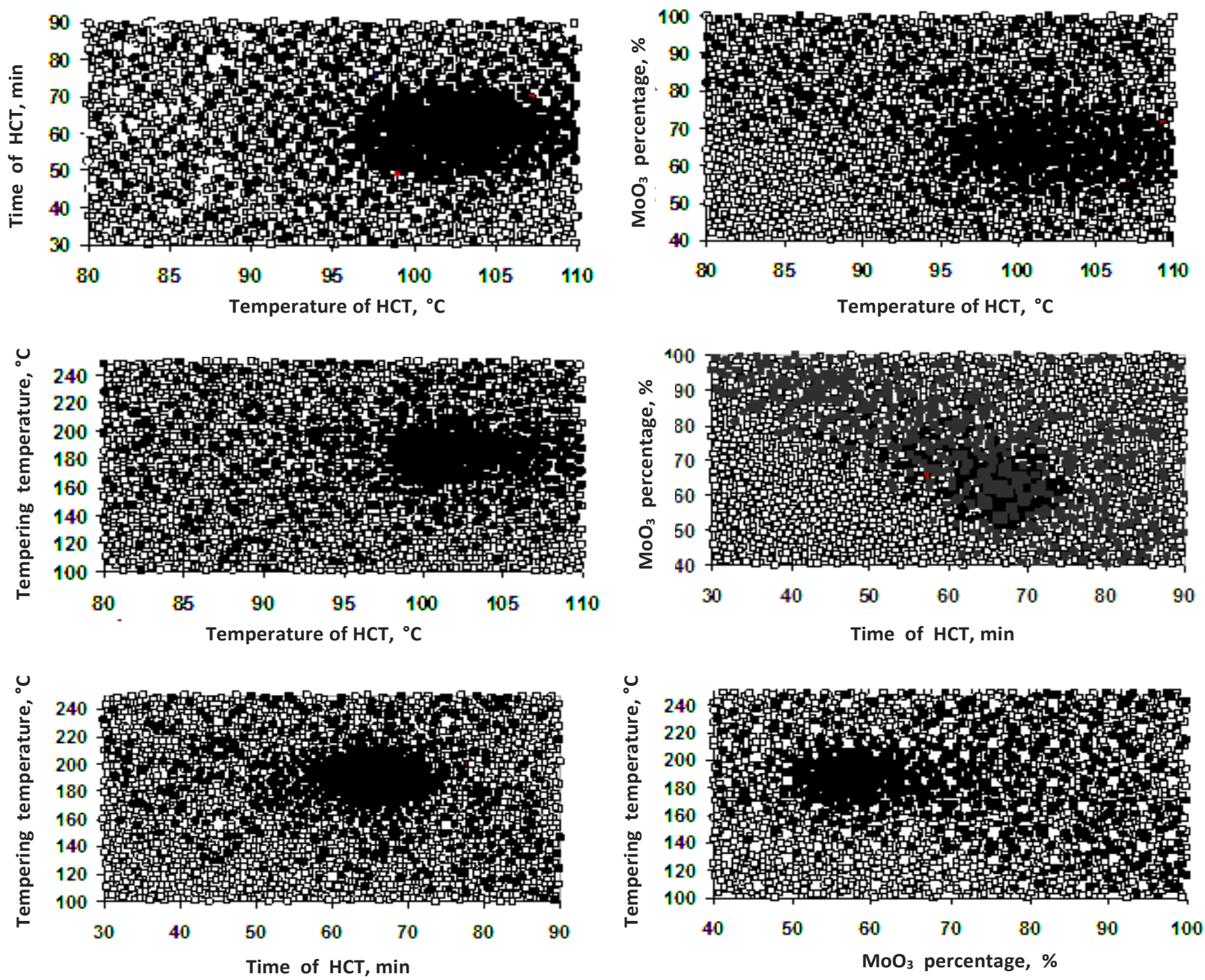

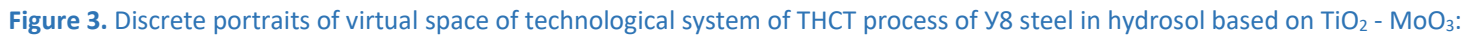

$\checkmark-$ variant of the system providing the set properties of y 8 steel; $\diamond$ - variant of the system not providing the set properties of y 8 steel. 


\begin{tabular}{|c|c|c|c|c|}
\hline Name of process parameter & Parameter value & $\begin{array}{l}\text { Manufacturing } \\
\text { tolerance value }\end{array}$ & $\begin{array}{c}\text { Manufacturing } \\
\text { tolerance margin }\end{array}$ & $\begin{array}{c}\text { Coefficient of process } \\
\text { system operability }\end{array}$ \\
\hline Temperature of hydrochemical treatment, ${ }^{\circ} \mathrm{C}$ & 100 & \pm 1 & 2 & 2,0 \\
\hline Time of hydrochemical treatment, min & 67 & \pm 1 & 2 & 4,5 \\
\hline MoO3 percentage in hydrosol oxides mixture, \% & 57 & \pm 1 & 2 & 4,0 \\
\hline Tempering temperature, ${ }^{\circ} \mathrm{C}$ & 189 & \pm 5 & 10 & 2,2 \\
\hline
\end{tabular}

Table 5. Manufacturing tolerance margins of technological system by input parameters

The allocation of stable domains in a multidimensional space of states is an important stage in the selection of a technically optimal variant of the system. The friction coefficient with desired level of $0.060-0.075$ is used as the optimization criterion (see Tab. 4). It is seen from Fig. 3 that the THCT technology of the $\mathrm{y} 8$ steel is implemented with high properties only when the system gets into the stable domain marked with dark dots. Overrunning of one or more parameters of the process beyond the stable domains into the domains marked with light dots is evidence that the material with the set properties in this case will not be fabricated.

As a result of solution of the problem of design of THCT technology of the $\mathrm{y} 8$ steel in the hydrosol based on $\mathrm{TiO}_{2}$ $\mathrm{MoO}_{3}$, the actual indices of its main tribotechnical property (Tab. 6), 100\% reproducibility of which is achieved upon exact compliance of the process parameters within manufacturing tolerances (see Tab. 5), were stated. The results of tests confirmed this too (Fig. 4).

\begin{tabular}{|c|c|c|c|}
\hline Name of index of & Rated & \multicolumn{2}{|c|}{ Scatter limits of index of properties } \\
\cline { 3 - 4 } properties & value & lower & upper \\
\hline Friction coefficient, $f$ & 0,067 & 0,065 & 0,069 \\
\hline
\end{tabular}

Table 6. Actual indices of $\mathrm{y} 8$ steel properties after THCT and their scatter limits by the results of virtual tests of technological system

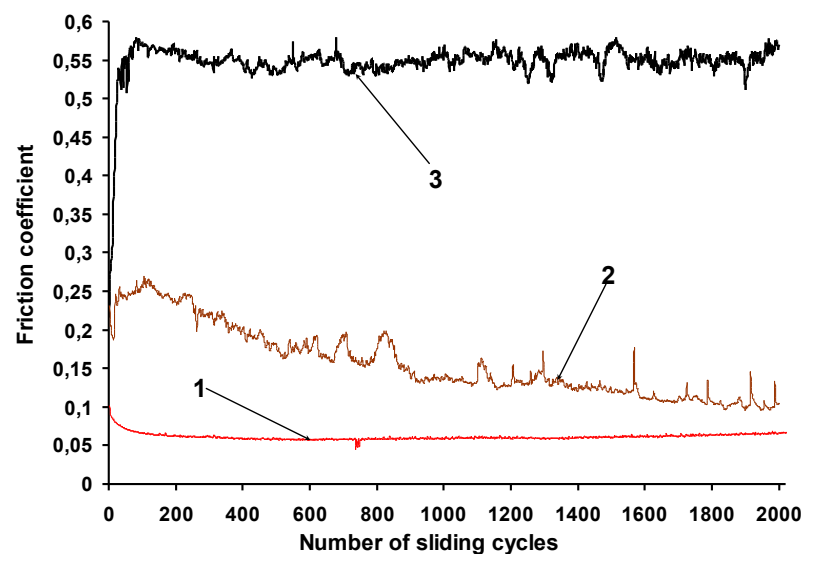

Figure 4. Comparative diagram of changes in friction coefficient vs. wear duration (without lubrication) of the surface of $y 8$ steel before and after THCT. Test conditions are dry sliding friction; friction pair is hardened Y8 steel (plane) - ШX15 steel (sphere $4 \mathrm{~mm}$ in diameter); load is $1 \mathrm{~N}$; stroke length (track) is $3 \mathrm{~mm}$; speed is $4 \mathrm{~mm} / \mathrm{s}: 1-\mathrm{y}_{8}$ steel after THCT in hydrosol of $\mathrm{TiO}_{2}-\mathrm{MoO}_{3}$ in optimal regime; $2-\mathrm{y} 8$ steel with diamond-like PVD coating; 3 - y8 steel (before treatment).

For any tool of which the place of contact with a machinable workpiece changes over time [Bel'skii 1984], it is important to have minimum and invariable values of the friction coefficient during the whole operating period. The thermo-hydrochemical coatings correspond to these demands; and this is their advantages against PVD diamond coating (see Fig. 4) and other well-known solid lubricating coatings [Vityaz' 2007].

\section{APPLICATION OF RESEARCH RESULTS}

The manufacturing testing results revealed that the THCT using aqueous-dispersion oxide and carbon compositions makes it possible to increase the resistance of various types of steel tools by $1.3-8$ times as compared with an unprocessed tool (Tab. 7).

\begin{tabular}{|c|c|l|c|}
\hline Type of tool & $\begin{array}{c}\text { Tool } \\
\text { steel }\end{array}$ & \multicolumn{1}{|c|}{ Test place } & $\begin{array}{c}\text { Increase in } \\
\text { tool } \\
\text { resistance, } \\
K_{W}\end{array}$ \\
\hline Thread taps & $\begin{array}{l}\text { High- } \\
\text { speed } \\
\text { steels } \\
\text { (HSS) }\end{array}$ & $\begin{array}{l}\text { Salyut, UMPO, PMZ (Russia), } \\
\text { BELAZ, MTZ (Belarus), VUHZ } \\
\text { (Czechia), Daewoo (S.Korea) }\end{array}$ & $1.7-4.5$ \\
\hline Band saws & HSS & VUHZ (Czechia) & $2.5-3$ \\
\hline Drills & HSS & $\begin{array}{l}\text { PS (Slovakia), VUHZ(Czechia), } \\
\text { Motovelo, BELAZ (Belarus), } \\
\text { Duks (Russia), }\end{array}$ & $1.8-2.9$ \\
\hline Core drills & HSS & Salyut, Iskra, VTZ (Russia) & $1.8-3$ \\
\hline Reamers & HSS & Motovelo, AGU, BATE(Belarus) & $1.5-2.7$ \\
\hline Broach & HSS & Motovelo (Belarus) & $2-2.5$ \\
\hline Cutting tools & HSS & Motovelo, BELAZ (Belarus) & $1.3-1.9$ \\
\hline Gear cutters & HSS & Motovelo (Belarus) & $1.6-2.1$ \\
\hline $\begin{array}{c}\text { Milling cutters } \\
\text { HSS }\end{array}$ & $\begin{array}{l}\text { Motovelo, BELAZ, MTZ } \\
\text { (Belarus) }\end{array}$ & $2-8$ \\
\hline $\begin{array}{c}\text { Fiberglass } \\
\text { cutting knives }\end{array}$ & HSS & Skloplast (Slovakia) & $1.9-2.2$ \\
\hline $\begin{array}{c}\text { Cold forming } \\
\text { stamps }\end{array}$ & $\begin{array}{l}\text { Punch } \\
\text { steels }\end{array}$ & $\begin{array}{l}\text { ZVL-LSA (Slovakia), BELAZ } \\
\text { (Belarus) }\end{array}$ & $1.8-2.5$ \\
\hline
\end{tabular}

Table 7. Test results of steel tool subjected to THCT

Considering Tab. 7, one should note that the highest indices of wear resistance of the cutting and punching tool were achieved upon treatment of hard-to-machine and nonferrous alloys. The technology of thermo-hydrochemical treatment was applied in Belarus at the BELAZ, Motovelo, MTZ plants, and other countries.

\section{CONCLUSIONS}

(1) The mathematical simulation and the computeraided design of the THCT process of $\mathrm{Y} 8$ steel in a hydrosol medium of $\mathrm{TiO}_{2}-\mathrm{MoO}_{3}$ using computer technologies of the method of multidimensional design synthesis of technical objects, materials, and technologies were implemented. The technically optimal regimes for implementing the process in manufacture with guaranteed achievement of the set properties of steel products subjected to THCT were determined.

(2) The treatment of y8 tool steel by the optimal THCT 
regime makes it possible to considerably (by 8.3 times) reduce the friction coefficient of the steel surface under sliding conditions without lubrication.

(3) The simple and economical method of thermohydrochemical treatment of tool steels has been developed, the use of which makes it possible to increase the operational resistance of different types of steel tools by 1.3-8 times in comparison with the traditional used method.

\section{Acknowledgements}

The research presented in this paper is an outcome of project No. APVV-16-0476 "Research and development of the progressive design of the high speed rotor mounting in spinning machines" funded by the Slovak Research and Development Agency.

\section{REFERENCES}

[Bel'skii 1984] Bel'skii, S.E. and Tofpenets, R.L. Structural Factors of Operational Strength of Cutting Tool - Minsk, 128 p., 1984.

[Cavaleiro 2006] Cavaleiro, A. and De Hosson, J.T. Nanostructured Coatings - New York: Springer-Verlag, 752 p., 2006.

[Hocking 1989] Hocking, M. G., Vasantasree, V. and Sidky, P. S. Metallic and Ceramic Coatings: Production, Properties and Applications - London, 518 p., 1989.

[Novik 1971] Novik, F.S. Mathematical Methods for Planning Experimens in Materials Science - Moscow, Chap. 4, 148 p., 1971.

[Polzer 1983] Polzer, G. und Meissner, F. Grundlagen zu Reibung und Verschleiß, Leipzig: VEB Deutscher Verlag für Grund- stoffindustrie Leipzig, 264 p., 1983.
[Shmatov 1998] Shmatov, A. A. Soft, inexpensive coatings prolong tool life: Advanced Coatings \& Surface Technology, 1998, Vol. 11, No. 1, pp. 5-6.

[Shmatov 2014] Shmatov, A., Soos, L. and Krajny, Z. Thermohydrochemical treatment for tool materials (a monograph) Bratislava, 115 p., 2014.

[Shmatov 2016] Shmatov, A., Soos, L. and Krajny, Z. Composite structure strengthening tools in an aqueous dispersed media (a monograph) - Bratislava, 139 p., 2016.

[Shmatov 2018] Shmatov, A., Soos, L. and Krajny, Z. Forming of diffusion multi-carbide coatings on tool alloys (a monograph) - Bratislava, 137 p., 2018.

[Vityaz' 1971] Vityaz', P.A., Zhilinskii, O.V. and Laktyushkina, T.V.: Computer-based selection of technically optimal variant in multicriteria tasks of design: Fiz. Mezomekh., 2004, vol. 7, pp. 3-11.

[Vityaz' 2007] Vityaz', P.A. Solid Lubricating Coatings in Machine Engineering - Minsk, 170 p., 2007.

\section{CONTACTS:}

Dr. Alexander Shmatov, docent, Ph.D. Belarusian National Technical University Faculty of Mechanical Engineering Nezavisimosti ave., 65, 220013 Minsk, Belarus Tel.: +375 293777 357, +375 447779213 e-mail: shmatovalexander@gmail.com 